\title{
Letter: Systematic Stereotactic Error Reduction Using a Calibration Technique in Single- \\ Brain-Pass and Multitrack Deep Brain Stimulations
}

Dear Editor

The recent publication on systematic stereotactic error reduction examines the stereotactic error between "intended coordinates" and final trajectory during implantation of 310 deep brain stimulation (DBS) leads in 166 patients. ${ }^{1}$ The authors observed a systematic targeting error that was dictated by the coronal angle of approach. They hypothesize that this error is secondary to a combination of MRI distortion, instrumental error and brain distortion by the advancing electrode through the non-rigid brain.

A calibration processes was adopted, modifying the "frame coordinates" from the "intended coordinates" to pre-empt and correct for this observed error. Targeting accuracy improved for both multi-pass and single brain pass surgical techniques. This simple maneuver led to a significant improvement in lead placement accuracy from $1.5 \pm 0.8 \mathrm{~mm}$ to $1.1 \pm 0.6 \mathrm{~mm}, \mathrm{p}<$ 0.000001

The uninitiated may dismiss this seemingly small numeric change as clinically irrelevant. However, in practice, it results in a significant reduction in the number of leads that are over $2 \mathrm{~mm}$ from the intended anatomical target, a clinically meaningful difference. ${ }^{2}$ These results are particularly interesting since they replicate those of a previous study from our own institution and suggest that a similar approach could be more widely implemented in other DBS centers. ${ }^{3}$ 
A recent US study reported an exceedingly high rate of lead relocation due to suboptimal placement in up to $16 \%$ of DBS procedures. ${ }^{4}$ In other words, up to 1 in 6 DBS procedures are revision operations, performed to rectify a targeting error that could have been avoided or immediately rectified during the initial procedure. This finding underscores the importance of obtaining routine postoperative stereotactic CT or MR imaging, irrespective of any clinical or neurophysiological observations made during surgery. Since the stereotactic frame is still in place, suboptimal lead location can be identified and remedied during the same procedure. Moreover, routine collection of such imaging data would provide an audit of targeting accuracy and allow development of a specific calibration method for that particular center.

Most importantly, the subsequent improvement in "first pass" accuracy will reduce the number of brain penetrations required for lead implantation, and consequently reduce the risk of hemorrhage, a rare but potentially devastating complication in stereotactic functional neurosurgery. ${ }^{5}$ For all these reasons, stereotactic imaging of the implanted leads prior to termination of the procedure should be considered a "standard of care" in DBS surgery.

Ludvic Zrinzo

London, UK

1. Park S-C, Lee JK, Kim SM, Choi EJ, Lee CS. Systematic Stereotactic Error Reduction Using a Calibration Technique in Single-Brain-Pass and Multitrack Deep Brain Stimulations. Oper Neurosurg (Hagerstown). 2017;67(2 Suppl Operative):437. doi:10.1093/ons/opx183. 
2. Ellis T-M, Foote KD, Fernandez HH, et al. Reoperation for suboptimal outcomes after deep brain stimulation surgery. Neurosurgery. 2008;63(4):754-60-discussion760-1. doi:10.1227/01.NEU.0000325492.58799.35.

3. Holl EM, Petersen EA, Foltynie T, et al. Improving Targeting in Image-Guided FrameBased Deep Brain Stimulation. Neurosurgery. 2010;67:ons437-ons447. doi:10.1227/NEU.0b013e3181f7422a.

4. Rolston JD, Englot DJ, Starr PA, Larson PS. An unexpectedly high rate of revisions and removals in deep brain stimulation surgery: Analysis of multiple databases. Parkinsonism and Related Disorders. 2016;33:72-77. doi:10.1016/j.parkreldis.2016.09.014.

5. Zrinzo L, Foltynie T, Limousin P, Hariz Ml. Reducing hemorrhagic complications in functional neurosurgery: a large case series and systematic literature review. Journal of Neurosurgery. 2012;116(1):84-94. doi:10.3171/2011.8.JNS101407. 